\title{
Catering For Individual Student Learning Preferences In Economics
}

Anthony Stokes, Australian Catholic University, Australia

Edgar Wilson, University of Wollongong, Australia

\begin{abstract}
There have been many national and international reports expressing concern about the problems of teaching economics subjects in universities and colleges. This paper puts forward one approach to deal with the issue through the use of a computer based learning program designed to cater for the differences in backgrounds and learning styles of economics students at the University of Wollongong, Australia.
\end{abstract}

Keywords: computer assisted learning, economics, prior learning backgrounds, WinEcon Fiscal Pathways, education, learning outcomes, key competencies

\section{INTRODUCTION}

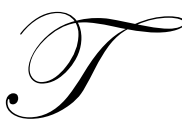

here have been many national and international reports expressing concern about the problems of teaching economics subjects in universities and colleges. Statton and McBride (1995) regard the great diversity of students as a major problem. Stokes and Wilson (1998a, 1998b) detail the many changes occurring in the make-up of the student population in economics courses in Australian universities. Historically, the great majority of students who enrolled in economics were recent year 12 Higher School Certificate (HSC) graduates who brought with them a common understanding of basic economics principles. This relative homogeneity allowed lecturers to plan subject content, and progression rates, through that content, with confidence. Now there is a growing heterogeneity amongst the candidature as a result of an increasing number of high school students who have no prior knowledge of economics and an increase in the number of students from overseas with some economics background, but with little knowledge of the Australian economy and institutions.

The 'easy' answer that is applied at most universities in Australia, and most likely globally, is to present a homogenous course and pitch the materials somewhere in the 'middle' using very clear, well structured examples and applications of methods of principles. Alauddin and Valadkhani (2003) point out that while such a strategy is rational in conception and might be highly popular if communicated well, it could potentially alienate students at both ends. For instance, the students at the bottom end might feel that the materials may not have enough practical examples, which can help them relate the classroom 'theory' to real world issues. On the other hand, the top-end students with more prior knowledge and/or greater ability, with the materials and resources and motivation to go further to explore the concepts at the deeper level than the 'process' and practical application of methods. If these needs remain unresolved, the students at both ends might feel, isolated, alienated and disenfranchised. This can potentially earn two types of unfavourable externalities: 'economics is too hard, abstract and not-real world oriented' and 'economics caters only for the mediocre students' or 'there is not enough challenge in economics courses'. Both types of externalities can engender disaffection with economics with attendant adverse effect on the enrolment. It is well documented that to-date economists may have chosen 'standards' rather than 'popularity' in view of the trends (Bloch and Stromback 2002, p.2).

According to Becker and Watts (1995) there have been many attempts to generate greater interest and enthusiasm in economics subjects over the last twenty five years. These mainly concentrated on using a variety of student centred teaching strategies. Whilst these approaches have merit, they are still based on the teaching of a common core of economics principles to all students irrespective of their prior economics knowledge or their personal interests and preferences. A number of national reports have emphasised the importance of considering 
students' prior economics knowledge and vocational requirements in post compulsory education and training (vide Finn, 1991, Mayer, 1992 and Carmichael, 1992). Another consideration, as suggested by Fleming (1995) and St Hill (1997), is the preferred learning style of students. Students have different preferred styles of learning. Some students have a preference for visual ways of representing information. Some prefer to learn by aural methods. Others have a preference for reading and writing textual information, while others have a preference for kinesthetic learning experiences and practices.

\section{ALTERNATE LEARNING PATHWAYS}

There were two approaches that we adopted to deal with these issues. The first was a phased modular approach in the teaching of the introductory first year macroeconomics course. As detailed in Stokes and Wilson (1998b) three modules of economics were offered in the first phase that lasted seven weeks. The modules were designed to suit students with no prior economics knowledge, some prior economics knowledge but little knowledge of the Australian economy (mostly international students) and those with significant economics knowledge (mostly studied economics at school in Australia). The students were free to determine which module they followed for the first seven weeks. Each module was taught in a way that catered for the needs of that group. At the end of the first seven weeks all groups were combined for a final seven week common module.

A full analysis of the first approach is found in Stokes and Wilson (1998b). The purpose of this paper is to discuss the second approach that was adopted that caters not only for student learning backgrounds but also different styles of learning. The second approach that we adopted was applied through a windows based computer assisted learning package. The package titled WinEcon Fiscal Pathways (FP) was designed to cater for students studying intermediate level Macroeconomic Theory and Policy. The module provides a 'journey of discovery' for these students as they explore a variety of learning experiences that provide a fuller appreciation and understanding of the implications of how fiscal policy may be used to promote economic growth in a global environment. This important topic was chosen as a basis for the computer based learning module as our experience showed that students are challenged both at conceptual and analytical levels in this part of the course. In addition, the differing backgrounds of student's prior economic and institutional knowledge can greatly influence their understanding of this topic. The package attempts to overcome these problems by offering students alternate learning pathways which are designed to better suit their prior learning backgrounds and needs. Students with the guidance of a learning map choose the pathway they feel is the most suitable for them. They are allowed to explore alternative routes and obtain feedback on their progress along each pathway.

WinEcon FP provides a journey of discovery for students as they explore a variety of learning experiences that will provide for them a fuller appreciation and understanding of the implications of fiscal policy. We do this by offering four alternate pathways to student learning. The pathways are based on two features of their prior learning backgrounds, namely their understanding of economic theory and principles and secondly their degree of understanding of relevant economic institutions. The first pathway is designed for students with a strong understanding of economic theory and principles, and a good knowledge of economic institutions (Strong Economic and Institutional Background). The second pathway caters for students with strong prior economics but with little institutional knowledge (Strong Economic and Little Institutional Background). The third pathway is relevant for students who feel they have only a basic understanding of economics but a good understanding and knowledge of economic institutions (Basic Economic and Strong Institutional Background). The final pathway is designed for students with a basic understanding of economics and little institutional background (Basic Economic and Little Institutional Background).

Students, with the aid of a learning map, can choose the pathway that they feel is most suitable to their prior learning backgrounds and needs. If the pathway the student has chosen is not suitable, they may change to another pathway. At all times students are free to explore different activities, go anywhere on the learning map, travel in any direction, visit any location and stay as long as they wish. However the learning map has been designed to reduce the chance of students becoming lost, mistakenly bypassing important activities or becoming distracted so that their progress is slowed unnecessarily. Throughout the journey students obtain feedback and are required to monitor their progress according to their proficiency in conducting interactive exercises, Web exercises, policy simulations, answering questions, as well as submitting tutorial exercises and a project. Students also evaluate their 
progress by recording their learning experiences in a diary. All of these activities form an important worksheet guide for students, which is closely integrated into the subject structure and content.

The journey includes common destinations that provide core information and learning activities that are relevant for all students. Important core concepts are dealt with along the alternate pathways in a manner appropriate to the needs and backgrounds of the students. For example, the analysis of the determinants of international trade and exchange rates at the beginning of Stage V can be approached in four different ways. Students with a basic level of economic understanding are led through the process of exchange rate determination using a transparent sequential process for fixed and flexible exchange rates and then a graphical derivation of the BP curve, which many students will still find challenging. Those with a strong understanding of economic theory and principles will analyse the international arbitraging of exchange rates, supply and demand analysis and derivation of the BP curve. This exercise requires a higher level of analysis and mathematical competency. Students from each of these two groups who wish to find out more about institutional trading patterns can decide to visit an interactive site that provides detailed information on international and regional trading patterns over time and for different sectors.

All of the learning activities have been grouped according to their complexity, relative size and expected average time required. The cities visited in the journey are by nature large and complex, offering a variety of learning experiences. On the other hand towns and villages offer only one or a few learning experiences. The journey of discovery is broken into the following five stages:

1. Economic development and welfare

2. Time series data analysis

3. Modelling fiscal policy

4. $\quad$ Further policy considerations

5. Fiscal policy and the open economy

Each will be reviewed in terms of the desired key competencies we wish to achieve for each stage.

\section{COMPETENCIES}

are:

The Key Competencies are based on Mayer's (1992) review. The seven main categories of competencies

- $\quad$ KC1 Collecting, analysing and organising information
-
KC2 Communicating ideas and information
-
KC4 Working and organising activities
KC5 Using mathematical ideas and techniques
- $\quad$ KC6 Solving problems
KC7 Using technology

Stage I requires students to consider the difficulties in defining and measuring economic development and welfare. The purpose here is to introduce students to some advanced concepts, including the construction of a Human Development Index and an analysis and evaluation of its sensitivity to changes in component parts, for different countries (key competencies identified in Mayer (1992) are KC1,5,6). Students can search and analyse an international data base and optionally visit three institutional Web sites which include relevant exercises as per the example below $(K C 1,3,6,7)$. A tutorial discussion exercise is required to be submitted at the end of this stage ( $K C 1$ 4). Stage II is designed to give students hands on experience in working with and analysing macroeconomic data using spreadsheets and formulas $(\mathrm{KCl}, 3,5-7)$. This exercise is designed to complement the concepts, knowledge and skills students will have acquired in the first stage. The correlation analysis, detailed with appropriate exercises as an optional excursion, is used to determine pro and counter cyclical variables $(\mathrm{KCl}, 3,5-7)$.

Having been introduced to the cyclical data, Stage III formally models how fiscal policy may affect output and its fluctuations. Some students may find parts of this theoretical section difficult in terms of analytic detail and 
economic concepts and principles. The closed economy IS LM model is therefore developed in alternate ways and students need to choose the pathway appropriate to their backgrounds and needs $(K C 5,6)$. Both paths cover the same core material. The paths then converge to cover common material which finishes with a challenging fiscal budget policy simulation exercise $(K C 1,3,6,7)$. Students, who are unfamiliar with the Australian Treasury budget process, are advised to take the optional Web excursion to the Budget Papers and complete the assigned exercise. A tutorial discussion exercise is required to be submitted at the end of this stage $(K C 1-4,7)$.

Stage IV considers the complexities involved in using short run discretionary fiscal policy to stabilise the economy. The purpose of this section is to identify the difficulties in practice of judging the timing and magnitude of policy changes. As before, separate paths are recommended with both paths requiring students to vary parameters to simulate possible beneficial and harmful consequences of stabilisation policy $(K C 1,5,6)$. The final stage expands the IS LM model developed in Section III to an open economy model. Again, different paths are nominated which both consider the consequences of floating exchange rates and the Balance of Payments on fiscal policy. If students require institutional details on international trade then there is an optional excursion $(\mathrm{KCl})$. The paths then converge to analyse the complete IS LM BP model with flexible exchange rates facing various exogenous shocks $(K C 5,6)$. A non trivial fiscal policy simulation exercise then follows $(K C 1,3,6,7)$. Students who require further institutional knowledge about exchange rates are advised to visit the Reserve Bank's web site, read a particular Reserve Bank Bulletin article and complete an exercise $(K C 1,3,7)$. At the completion of all five stages there is a final task which requires students to write and submit a 1,000 word report.

Whilst not compulsory, students are also encouraged to submit a summary (of length of their choosing) on their learning experiences from their travel diaries $(K C 1,2,3,6,7)$. In addition to these tasks, navigating WinEcon Fiscal Pathways and keeping a diary increases the overall competencies required of students to effectively plan the pathways they will take, set goals and priorities, manage time, evaluate their progress and effectively use the technology $(K C 1,3,4,7)$. It is important to note that the key competencies $\mathrm{KC} 3,4$ and 7 feature throughout and are embedded in the learning activities of WinEcon Fiscal Pathways.

\section{LEARNING OUTCOMES}

It is intended that WinEcon Fiscal Pathways will greatly improve learning outcomes according to the 'Attributes of a Wollongong Graduate - Strategic Plan 1997-2005'.

That is, graduates should, inter alia, have coherent and extensive knowledge in the economics discipline, be able to analyse critically, reason logically, solve problems and be willing to initiate and participate in change. The expected outcomes include that the students should:

- $\quad$ have a knowledge and understanding of the working of Australian fiscal policy;

- $\quad$ have an understanding of the important assumptions of the economic theories;

- $\quad$ demonstrate an understanding of the strengths and weaknesses of the relevant

- $\quad$ models as applied to the Australian and global economy;

- $\quad$ have an understanding of Australia's place and role in the global economies;

- $\quad$ be able to examine, interpret and apply written information and graphical and

- $\quad$ statistical data;

- $\quad$ be able to evaluate economic evidence used in support of economic arguments;

- $\quad$ be able to use economic tools to solve problems;

- $\quad$ reach conclusions that are based on economic reasoning; and

- $\quad$ be able to make informed and reasoned judgements about fiscal policy issues. 


\section{CHARACTERISTICS OF STUDENTS STUDYING MACROECONOMICS 2 - THEORY AND POLICY - AT THE UNIVERSITY OF WOLLONGONG}

The subject had 104 students enrolled at the time of the initial survey. From the sample of students, 39\% were born in Australia, 53\% were born in South East Asia and 8\% were born elsewhere overseas. The proportions for the student's country of residence were very close to the country of birth values. In terms of students backgrounds $28 \%$ had not studied economics prior to starting university. For the students who had studied economics previously, $39 \%$ had studied economics at secondary school and completed the HSC, $11 \%$ had studied economics at either TAFE, foundation studies or elsewhere in Australia, whilst a large 51\% had studied economics overseas. Table 1 shows the first year macroeconomic grades of these categories of students. Clearly, the HSC students coming into the second course of macroeconomics are better prepared than all the others, whilst students with 'other Australian' and overseas prior economics performed relatively poorly. Students who had not studied economics previously formed an interesting bimodal distribution suggesting that a proportion of these students have achieved a distinction grade whilst the other major grouping have obtained a pass grade.

Table 1: Percent Distributions of ECON205 Students First Year Macroeconomics Grades by Prior University Economics Background

\begin{tabular}{|l|c|c|c|c|c|}
\hline \multicolumn{1}{|c|}{ Grade } & $\begin{array}{c}\text { No prior } \\
\text { knowledge }\end{array}$ & $\begin{array}{c}\text { HSC - Yr 12 } \\
\text { school }\end{array}$ & Other Australian & Overseas & All students \\
\hline Fail & 0 & 0 & 0 & 0 & 0 \\
\hline Pass Conceded & 9 & 3 & 0 & 0 & 4 \\
\hline Pass & 41 & 10 & 44 & 41 & 31 \\
\hline Credit & 14 & 52 & 22 & 36 & 34 \\
\hline Distinction & 27 & 28 & 22 & 14 & 23 \\
\hline High Distinction & 9 & 7 & 11 & 9 & 9 \\
\hline
\end{tabular}

The students were also questioned about their preferred learning styles. To this end we used Flemming's (1995) approach to determine students preferred modes of intaking, processing and outputting information as applied by St Hill (1997). This approach is called VARK because of the four modes:

- $\quad V$ Preference for visual ways of representing information, for example video, graphic and symbolic ways

- $\quad A$ Preference for learning by aural methods, for example by listening and talking

- $\quad R$ Preference for reading and writing textual information

- $\quad K$ Preference for kinesthetic learning experiences and practices.

Students were asked to respond to each of the thirteen questions by nominating any one or more of the above modes as appropriate for them. The average number of responses for each mode were 3.7 for $V, 3.5$ for $A, 5.0$ for $R$ and 4.0 for $K$. Whilst textual preference was ranked the highest, the other modes were also significant, implying that visual, audio and kinesthetic are important modes of processing information by these students. A few examples show the variability of student preferences. For some, only one mode dominated (V,A,R, K = 3,8,0,2 for a HSC student who got $66 \%$ on the mid-session test whilst another HSC student who got $60 \%$ scored 9,3,2,6 and another overseas student who got $84 \%$ scored $4,3,8,4)$. Others scored low in all modes $(3,2,2,4$ for a student with no prior economics and who got $70 \%$ on the mid-session test and another overseas student who got $42 \%$ scored $6,8,6,7)$. We interpret these findings of heterogeneous preferences as further evidence of a need for an approach that will cater for individual learning preferences, such as those possible in computer based learning which includes multimedia in a meaningful fashion.

\section{EVALUATION OF EFFECTIVENESS}

WinEcon FP package has being used in the second year subject ECON205 Macroeconomic Theory and Policy. It generally requires about 12 hours of teaching time to work through the package. While the exposure to WinEcon Fiscal Pathways has been limited, we have survey data and progressive assessment results that demonstrate the success of the WinEcon FP package. 


\section{SURVEY RESULTS}

A survey was conducted in week ten of the semester. $79 \%$ of the students said their interest in computer based learning had increased since using the package, whilst $20 \%$ had not changed their interest and one student's had fallen. Only $4 \%$ of students thought the program was useless or distracting, $17 \%$ had no feelings, $61 \%$ and $17 \%$ respectively thought the program was a helpful or very helpful learning aid. When asked how the program has affected students understanding of the material, $82 \%$ said it had been helpful, 7\% believed it was very helpful, whilst $10 \%$ experienced no change. Students believed the program's navigation aids were helpful or very helpful (60\% and $14 \%$ respectively) with $14 \%$ having no feelings.

When WinEcon Fiscal Pathways was compared to the original WinEcon package ${ }^{1}$, one student thought it was worse, $28 \%$ of students had no feelings, yet $60 \%$ believed it was better and $8 \%$ thought it a lot better. We expect these views reflect inter alia, our attempts to help students navigate their way through the program; to integrate the package into the course; and to provide alternative learning modes according to the students VARK responses.

\section{TEST RESULTS}

Students were given two tutorial surprise tests worth $5 \%$ each and a mid-semester test worth $20 \%$. The first surprise test and the mid-semester test were conducted prior to the students being introduced to the package. The second surprise test was given to the majority of students after they had been exposed to the package in formal laboratory sessions. One tutorial was treated as a control group by having normal tutorials and not being given any access to the package during this time. The second test consisted of eight multiple choice questions which were selected from the mid-session test and which had an average mark of $60 \%$, which compares with the mid-semester test average mark of $60.5 \%$. Students answered the mid-semester test on the test paper which was collected at the end of the exam period and not returned or solutions given. The selected questions and distractors were re-ordered and the wording was modified where appropriate. The results for the non control group improved from the midsemester test average of $60.4 \%$ for this group to an average of $69.5 \%$ for the second surprise test. This increase of just over 9 percentage points was achieved despite the surprise element of the second test! In comparison, the average mark for the control group of sixteen students who were given the alternative standard tutorials, denied access to the package and who sat the same tests as the non control group, fell from $60.8 \%$ for the mid-session test to an average of $45.0 \%$ for the second surprise test.

\section{CONCLUSION}

These results support and are consistent with the favorable survey evaluations by students reported above which say that the majority of students found the package to be a helpful learning aid which increased their understanding of the material. We believe a computer based learning system that allows greater flexibility in student learning does promote increased interest in and understanding of the subject matter. It is important for economics educators to realise that students do have different interests, backgrounds and preferred styles of learning and that we structure courses and teaching methods that cater for these.

\section{AUTHOR INFORMATION}

Dr. Anthony Stokes is the Head of the School of Arts and Sciences (NSW\&ACT) and senior lecturer in economics at the Australian Catholic University in Sydney. He has written extensively in areas relating to the economics of education and he has been awarded three university awards for teaching excellence, including an Australian Government University Teaching Award for Economics.

Associate Professor Edgar Wilson is a former Head of the School of Economics at the University of Wollongong in Australia. He has received the University of Wollongong's award for teaching excellence and has researched extensively in the areas of macroeconomics, economic modelling, economic growth and productivity.

\footnotetext{
${ }^{1}$ WinEcon interactive CBL package was launched in the UK in 1995. In 2000, $85 \%$ of all UK university economics departments used the package and internationally, WinEcon is used at more than 250 sites worldwide.
} 


\section{REFERENCES}

1. Alauddin, M. and A. Valadkhani (2003) 'Causes and Implications of Declining Economics Major: A Focus on Australia'. Faculty of Commerce - Papers, University of Wollongong

2. Becker, W. and M. Watts (1995), 'Teaching Methods in Undergraduate Economics'. A paper given at the Australian Economics Education Symposium.

3. Bloch, H. and Stromback, T. (2002) 'The economics of strategy and the strategy of economics', Economic Papers, 21(1), pp.1-10.

4. Carmichael, L. (1992), 'The Australian Vocational Certificate Training System'. A Report to the National Board of Employment, Education and Training and Skills Foundation Council, Commonwealth Government of Australia, Canberra.

5. Finn, B. (1991), 'Young People's Participation in Post Compulsory Education in Training', Report to the Australian Education Council Review Committee.

6. Flemming, N. (1995), 'I'm Different Not Dumb: Modes of Presentation (VARK) in the Tertiary Classroom', presented at the Annual Conference of the Higher Education Research and Development Society of Australasia, Rockhampton, July.

7. Mayer Committee (1992), 'Employment—Related Key Competencies: A Proposal for Consultation', Melbourne.

8. St Hill, R. (1997), 'Modal Preferences in Teaching and Learning Economics', Proceedings of the Fifth Annual Teaching Economics Conference, University of Southern Queensland, Toowoomba, 2-4 July, pp. 53-79.

9. Stokes, A. and E. Wilson (1998a), 'Catering for First Year Economics Students Heterogeneous Needs and Prior Economics Backgrounds: An Application of CBL at the University of Wollongong', presented at the Sixth Annual Teaching Economics Conference, Macquarie University, 16-17 July.

10. Stokes, A. and E. Wilson (1998b), 'Catering to Individual Introductory Macroeconomics Students Needs: Streaming Students Based on Their Prior Learning Backgrounds', presented at the 27th Conference of Economists, University of Sydney, 28 September - 1 October.

11. Stratten, P. and G. McBride (1995), 'What Should We Teach in an Economics Foundation Studies?', presented at the Australian Education Symposium.

12. University of Wollongong (1997), 'Attributes of a Wollongong Graduate', Strategic Plan - 1997 - 2005. 
NOTES 